\title{
Predicting Consumption: A Lesson in Real-Time Data
}

\author{
Riccardo DiCecio and Charles S. Gascon
}

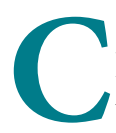
ontinuing crises in U.S. housing and financial markets have increased concerns about an impending recession, which typically involves two quarters of negative GDP growth. All recessions since the early 1950s, except the one in 2001, included a contraction in personal consumption expenditures (PCE). Because roughly 70 percent of the country's GDP can be attributed to PCE on goods and services, any contraction in consumption expenditures weighs heavily on economic growth.

The Bureau of Economic Analysis (BEA) measures GDP and, two months after the end of each quarter, releases its GDP estimates for that quarter. ${ }^{1}$ In addition to releasing data on total output, the BEA releases data on each component of GDP: PCE, investment, government expenditures, and net exports. Unlike the other components, PCE estimates are also released monthly as part of the BEA's "Personal Income and Outlays" report. Quarterly PCE is the average of monthly PCE over the three months in the quarter, and both monthly and quarterly data are subsequently revised multiple times.

These monthly PCE releases have been spotlighted recently: As it turns out, the PCE measure for the second month of a given quarter is close to the measure for the entire quarter. For example, the PCE for February 2008 (reported March 28) was $\$ 8,365.5$ billion; the advance release of 2008:Q1 PCE (reported May 1) was $\$ 8,369.1$ billion. The rationale for using the second month as a proxy for a quarter's average is simple: It is available soonerone month before the advance release of the quarterly figure. It is also quite reliable: On average, the economy tends to grow; if the growth rate of consumption from month to month within a quarter is constant, the PCE for the second month is close to that quarter's average.

The chart plots the approximated (second-month) and actual growth rates of PCE since 1991 using real-time data: That is, the growth rates at each point on the chart are computed using only the data that would have been available to a researcher at the time of the estimate. The approximated measure for 2008:Q3 is -2.3 percent, suggesting the first decline in PCE since the fourth quarter of 1991. On average, the second-month PCE is close to the reported quarterly data; however, it under predicts the advance release by an average of 0.15 percentage points over the sample. The correlation between the two series in the chart is 0.90 .

Most of the difference between the two series disappears when data are revised. In fact, the actual quarterly PCE growth rate and the approximation using second-month data is almost perfect, differing by only 0.03 percentage points when both growth rates are computed using current data. In summary, this simple calculation can provide a quite accurate picture of the quarterly consumption growth rate a month ahead of the BEA's first official release. In addition, the use of real-time (or unrevised) data is essential for evaluating the performance of this or any calculation.

\footnotetext{
${ }^{1}$ Both the GDP and the "Personal Income and Outlays" releases are available at http://www.bea.gov/national/index.htm. The current release schedule for the National Economic Accounts is available at http://www.bea.gov/newsreleases/ news_release_sort_national.htm.
}

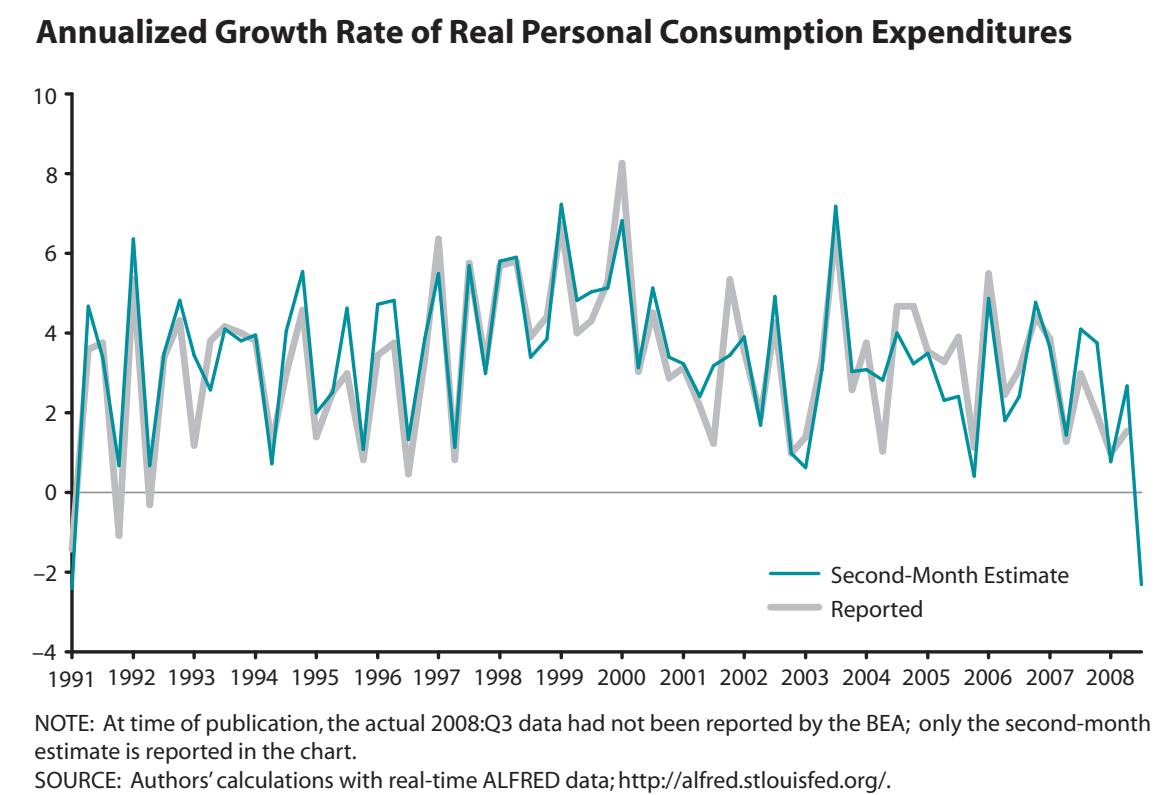

